\title{
Seed coat phytochemistry of both resistant and susceptible seeds affords some protection against the granivorous beetle Callosobruchus maculatus.
}

Taghread Hudaib, School of Pharmacy, University of Lincoln, Lincoln, LN6 7TS, UK. Email: thudaib@lincoln.ac.uk

William Hayes, School of Life Sciences, University of Lincoln, Lincoln, LN6 7TS, UK. whayes@lincoln.ac.uk

Sarah Brown, Applied materials technology ltd, Lyndon Business Park, farrier road, Lincoln, LN6 3RU.

sarahappmat@gmail.com

Paul E. Eady, School of Life Sciences, University of Lincoln, Lincoln, LN6 7TS, UK.

peady@lincoln.ac.uk

\begin{abstract}
The seed coat lies at the interface between the internal structures of the seed and the external environment and thus represents a key arena in the study of seed-herbivore interactions. Callosobruchus maculatus is a cosmopolitan pest of legume seeds, and under post-harvest conditions, females interact directly with the seed testa prior to laying their eggs. Here we investigate the effect of chemical extracts of the seed coat of the resistant Phaseolus vulgaris and the susceptible Vigna unguiculata beans on egg laying preferences and larval development of $C$. maculatus. Seed coat extracts contained phenolic, glycoside and alkaloid compounds. Upon re-incorporation of extracts into artificial host beans it was found that that several seed coat extracts from both the resistant and susceptible varieties reduced female oviposition and disrupted larval growth and development. However, none of the extracts assayed resulted in complete ovipositional or developmental failure suggesting that complete resistance in $P$. vulgaris is derived from other physical or chemical properties of the seed
\end{abstract}


and/or seed coat that function either alone or synergistically. Further work is required to elucidate the importance of synergistic interactions between different physiological defence mechanisms on overall plant (seed) resistance.

Key Words: Kidney beans; Phytochemicals; Volatiles; Bioactivity; Bruchidae.

\section{Introduction}

High concentrations of nutrients in the endosperm make seeds an ideal source of food for a range of animals (Fenner \& Thompson 2005). This in turn results in counter-selection on plants to evolve adaptations that reduce the likelihood of seeds being detected (Porter 2013) or consumed or digested (Rodgerson 1998). These defences are frequently found in the seed coat as this represents the interface between the internal structures of the seed and the external environment (Souza \& Marcos-Filho 2001; Zeng et al. 2004).

The seeds of many legumes, for example the cowpea (Vigna unguiculata), form an essential element in the diet of human populations (Fatokun 2002). However, post-harvest losses to granivorous insects, especially bruchid beetles can be as high at 90\% (Umeozor 2005). One of the most important bruchid pests is Callosobruchus maculatus (Coleoptera: Bruchidae). Under laboratory conditions, female $C$. maculatus readily lay their eggs on several species of host seed. However, the first instar larvae can only penetrate the testa of relatively few species (Janzen 1977), indicating the seed coat of many legume species affords protection against bruchid beetles.

A key methodological approach in understanding the mechanisms by which seeds protect themselves against herbivory has been to compare the physical and chemical profiles of resistant and susceptible seeds. For example, Silva et al. (2004) found little difference in the thickness or levels of cyanide in the seed coat of the resistant red kidney bean $(P$. vulgaris) and the susceptible cowpea. By contrast, they did find high levels of vicilin in the seed coat of $P$. vulgaris, suggesting that this protein affords protection against herbivory by 
C. maculatus. However, the phytochemistry of the seed coat of $P$. vulgaris and V. unguicuata differ in several other respects (Abdel-Sabour et al. 2010), rendering it difficult to pinpoint the exact mechanism of phytochemical defense without bioassays of different seed coat fractions.

The incorporation of allelochemicals into artificial seeds (Janzen et al. 1977; Shade et al. 1986; Macedo et al. 1993; Soares et al. 2007; Hudaib et al. 2013) allows those chemical groups that confer resistance to bruchid infestation to be identified. This method was first used by Janzen et al. (1977) to study which phytochemical groups confer seed resistance to C. maculatus. They found alkaloids and non-protein amino acids to be highly toxic to larval development. Vicillins-like 7S storage proteins have been found in the testa of various legumes and linked to seed resistance to herbivory (Oliveira et al. 1999; Moraes et al. 2000; Souza et al. 2012), as have lectins, lectin-like $\alpha$-amylase inhibitors and arcelin (Ishimoto \& Kitamura 1989).

However, seeds defend themselves with an arsenal of secondary compounds (Janzen 1977; Odeyemi et al. 2008) that sometimes work synergistically to reduce granivory (Bekele \& Hassanali 2001). Thus, assays of the toxicity of other phytochemical groups on the growth and development of $C$. maculatus are necessary to understand more fully the mechanisms by which seeds avoid herbivory and to identify potential targets for the development of resistant cowpea cultivars (Srinivasan \& Durairaj 2007). Here we report the results of phytochemical screens of seed coat extracts derived from the resistant $P$. vulgaris and the susceptible $V$. unguiculata, in conjunction with assays of their bioactivity against $C$. maculatus, using artificial seeds.

\section{Materials and methods}

2.1 Insect cultures. The beetles, Callosobruchus maculatus (Coleoptera: Bruchidae), used in this study were derived from Niamey, Niger (Eady et al. 2000) and have been under 
laboratory culture on black-eyed beans (Vigna unguiculata) for approximately 14 years at $27^{\circ} \mathrm{C}$ and $\sim 35 \%$ rh. Females used in the experimental protocols reported here were all originally virgin and approximately $48 \mathrm{~h}$ post eclosion. Virgins of known age were collected by isolating egg-laden seeds in the individual wells of 25 cell repli-dishes. All females were mated to virgin males prior to being used in the experiments.

2.2 Seed coat extraction. Two kilograms of black-eyed beans ( $V$. unguiculata) and $2 \mathrm{~kg}$ of red kidney-beans ( $P$. vulgaris) were soaked in distilled water for 30 and $45 \mathrm{~min}$ respectively to remove the seed coat. The seed coats were left to dry at room temperature before being milled into fine flour. Solvent extraction methods based on solvent polarity (Doughari, 2012) were used to extract different phytochemical groups from the seed coat flours. Where yield was expected to be low, Soxhlet extraction was applied (Jayaprakasha et al., 2001). Four solvents were used: $70 \%$ ethanol, $100 \%$ methanol, $100 \%$ acetone and $100 \%$ chloroform. For each solvent $100 \mathrm{~g}$ of milled seed coat was added to $500 \mathrm{ml}$ of solvent and the extraction process continued until the solvent filtrate appeared colourless, indicating most soluble constituents have been extracted (Audu et al., 2007). Extracts were suction-filtered and evaporated to dryness under vacuum in a rotary evaporator (Rotavapor ${ }^{\circledR} \mathrm{R}-210 / \mathrm{R}-215$ ) at the boiling point of the solvent. The percentage yield for each extract was calculated as the weight of the dry extract divided by the initial dry weight of the ground seed testa. Dry extracts were kept at $2^{\circ} \mathrm{C}$ prior to use in bioactivity assays.

2.3 Volatile and phytochemical analysis of extracts. Volatiles from the different extracts were analysed using headspace injection; volatiles of different bean extracts were analysed by GC/MS (Shimadzu GC/MS-QP 2010 S) equipped with a SUPELCOW AX ${ }^{\mathrm{TM} 10}$ capillary column $(30 \mathrm{~m} \times 0.25 \mathrm{~mm} ; 0.25 \mu \mathrm{m}$ film thickness) with helium as the carrier gas at a flow-rate of $1 \mathrm{ml} / \mathrm{min}$. The oven temperature programmed from $50^{\circ} \mathrm{C}$, hold $5 \mathrm{~min}, 50-240^{\circ} \mathrm{C}$ ramp at $5^{\circ} \mathrm{C} / \mathrm{min}$ and $240^{\circ} \mathrm{C}$ hold on for $20 \mathrm{~min}$. The injector and detector maintained at $250^{\circ} \mathrm{C}$. 
Headspace injection volume was $0.5 \mathrm{ml}$ and $4: 1$ split mode. The mass spectra were taken over the M/Z (35-500) range with an ionizing voltage of $70 \mathrm{eV}$. Identification of volatiles was performed by NIST / EPA / NIH 0.5 Mass Spectral Library search based on their Kováts retention indices. The Kováts retention indices for the temperature-programmed chromatography are calculated according to Kovats (1958).

2.4 Phytochemical screening tests and bioassays of seed coat extracts. Extracts from both legumes seed coat were subjected to standard phytochemical screening methods (Harborne, 1973; Odebiyi and Sofowora, 1978; Edeoga et al., 2005). Artificial seeds were prepared as described by Hudaib et al. (2013). Briefly, decorticated V. unguiculata seeds were ground into fine flour, which was then mixed with water $(20 \mathrm{ml}$ per $100 \mathrm{~g})$ to produce a dough that was subsequently shaped into artificial seeds. Seed coat extracts were added to the $V$. unguiculata flour at $2.5 \mathrm{~g}$ extract $/ 100 \mathrm{~g}$ flour prior to making the dough. Artificial seeds containing no extract were the control.

Two females were allowed to oviposit for $3 \mathrm{~h}$ on either 10 artificial control seeds or 10 artificial seeds loaded with one of the respective seed coat extracts (i.e. females not offered a choice of seeds). Each treatment was replicated 20 times. Following oviposition, the number of eggs laid on the seeds was counted. The egg-laden beans were incubated at $27^{\circ} \mathrm{C}, 35 \% \mathrm{rh}$ and the number and timing of emerged offspring determined. Upon emergence, virgin male offspring were isolated in Petri dishes and their longevity (at $27^{\circ} \mathrm{C}$ and $35 \%$ rh) determined. To control for potential micro-environment effects, Petri dishes containing the virgin males were rotated daily. Male (offspring) elytra length, a proxy for body size (Wilson \& Hill 1989) was recorded.

2.5 Statistical analysis. An ANOVA was used to determine the effect of treatment (extract) on female fecundity and offspring size (elytra length) whilst larval development time was analysed via a Kruskal-Wallis test using IBM SPSS version 21.0 (IBM Corp., Armonk, NY.). 
Binomial logistic regression and Cox proportional hazards model (performed in $\mathrm{R}$ version 2.15.2) were used to analyse egg-to-adult survival and offspring longevity, respectively (Crawley 2002). Male elytra length was included as a covariate in the latter model.

\section{Results}

3.1 Phytochemistry of seed coat extracts. Phytochemical screening of the extracts (Doughari, 2012) revealed the seed coats of both $P$. vulgaris and $V$. unguiculata to be rich in a variety of phytochemicals (Table 1). No qualitative differences were detected, although extracts of $P$. vulgaris tended to yield more positive readings, indicating higher concentrations in comparison to $V$. unguiculata. Kovats retention indices (RI) revealed the presence of $D$ limonene in the methanolic extract of $P$. vulgaris $(\mathrm{RI}=1197)$ whilst Dimethyl-disulphide $(\mathrm{RI}$ $=1073$ ) and Hexanal (RI 1197) were detected in the methanolic extract of $V$. unguiculata (Fig.1). No volatiles were detected in the chloroform, ethanol or acetone extracts using this method.

3.2 Bioassays of seed coat extracts. The addition of seed coat extracts to artificial seeds significantly affected the number of eggs laid $\left(A N O V A: F_{(6,125)}=12.74, P<0.001\right)$; the addition of methanol and chloroform extracts of both $V$. unguiculata and $P$. vulgaris reduced female oviposition (Fig. 2a). Larval development time was also affected by the addition of seed coat extracts to artificial seeds (Kruskal-Wallis; Chi-Square $=18.08, d f=6, P=0.006$; Fig. 2b); the addition of V. unguiculata chloroform extract and P. vulgaris ethanol extract resulted in the greatest reduction in development time (Fig. 2b). Logistic regression with a logit link function and binomial error (Crawley 2002) revealed a significant effect of treatment on egg-to-adult survival; $\Delta$ deviance $=34.91, d f=1, P<0.05$. The lowest egg-toadult survival rates were associated with the polar (methanol and ethanol) extracts of $P$. vulgaris (Fig. 2c). Offspring size (male elytra length) was also affected by the addition of seed coat extracts: $A N O V A F_{(6,124)}=21.54, \quad P<0.001$ (Fig. 2d). Chloroform extracts derived 
from the testa of both seeds resulted in small offspring as did the methanol extract of $P$. vulgaris. A Cox proportional hazard model revealed a significant effect of treatment (Likelihood ratio $=13.9, d f=6, P=0.03$ ) but not male size on male longevity (Likelihood ratio $=7.49, d f=7, \quad P=0.38)$. Addition of the $P$. vulgaris chloroform extract resulted in elevated male longevity (Fig. 2e). Male lifespan (eggs to adult death) was affected by treatment; Kruskal Wallis Test; Chi-Square $=23.18, d f=6, P=0.001$. Beetles that completed their development on artificial seeds loaded with the methanol and ethanol extracts of $P$. Vulgaris tended to have a reduced lifespan, whilst those grown on artificial seeds containing the chloroform fraction of $P$. vulgaris had the longest lifespan, despite the adults being relatively small (Fig. 2f).

\section{Discussion}

The results suggest the phytochemical profile of the seed coat of both resistant and susceptible varieties of bean afford some protection against granivorous beetles. Extracts of both the resistant $P$. vulgaris and the susceptible $V$. unguiculata diminished the propensity of female $C$. maculatus beetles to lay eggs and impacted larval growth and development. The chloroform extracts of both $P$. vulgaris and $V$. unguiculata reduced female oviposition. These extracts contained phytosteroids, a class of triterpeniods that can interfere with the metabolic pathways in insects (Després et al., 2007) and that are known to deter oviposition in insect pests. For example, application of cucurbitacin to host leaves deterred oviposition in the European cornborer (Ostrinia nubilalis) and the beet armyworm (Spodoptera exigua) (Tallamy et al 1997). Ingestion of phytoecdysteroids has also been shown to reduce larval weight in the Indian meal moth (Plodia interpunctella) (Rharrabe et al., 2010), possibly via phytoecdysteroids acting as Na/K-ATPase inhibitors (Després et al., 2007). Despite the methanolic extracts of $P$. vulgaris and $V$. unguiculata having quite different phytochemical profiles, both exhibited oviposition deterrent properties. Saponins were detected in the seed 
coat of $V$. unguiculata but not $P$. vulgaris. Saponins have known insecticidal activity, affecting the passage of food through the gut, the gut microflora, the uptake of sterols and membrane permeability (De Geyter et al 2007). However, the saponin containing extracts of V. unguiculata had little effect on larval growth and development (Fig. 2). Thus the type, concentration and profile of saponins (Ha et al. 2013) is likely to affect their bioactivity.

By contrast the methanolic extract of $P$. vulgaris contained phenolic compounds and terpenoids. Terpenoids are known to interact with the cholinergic system, the GABA system and the octopaminergic system, all of which could account for their insecticidal properties (Ratten 2010), whilst phenolic compounds have been shown to inhibit mitochondrial activity (Ratten 2010). That insect oviposition is deterred by the presence of terpenoids has been shown in the diamondback moth (Plutella xylostella) by Qui et al (1998). Phenolic compounds have also been shown to deter oviposition in the bruchid beetle Callosobruchus chinensis (Upasani et al 2003; Salunke et al 2005). The GCMS analysis of the methanolic extracts of both bean types revealed the presence of both D-limonene and dimethyl disulphide. D-limonene has known oviposition deterrent properties (Hudaib et al 2010) whilst dimethyl disulphide (a neurotoxin; Dugrarot et al 2003) has been shown to deter oviposition in the cabbage root fly (Delia radicum) (Ferry et al 2009). Thus the anti-oviposition properties of the methanolic extract could result from several phytochemical compounds within this extract.

Larval survival was lowest on the artificial seeds that incorporated the $P$. vulgaris methanolic extract with the most likely candidate antibiosis phytochemicals being the terpeniods and phenolics (see above). This extract also resulted in the smallest offspring (as determined by elytra length) providing further evidence that this extract was toxic to $C$. maculatus larvae. Offspring size was also affected by the addition of the chloroform extract to the artificial seeds. This extract contained steroids, some of which have anti-feedant 
properties (Rharrabe et al., 2010; Jing et al. 2012). The 70\% ethanolic extract of $P$. vulgaris also resulted relatively low egg-to-adult survival. This could be due to the high levels of tannins and saponins (see above) found in this fraction. Onuh and Onyenekwe (2008) found high levels of tannins and saponins in the seed coats of resistant $V$. unguiculata cultivars. The addition of the chloroform extract of $P$. vulgaris to artificial seeds resulted in an increase in adult longevity despite causing a reduction in adult size at eclosion. This is surprising because size and longevity tend to be positively associated in C. maculatus (Eady et al. 2007). The enhanced longevity of these males could be a result of plant sterols being a limited essential resource for insects (Janson et al 2009) or through the reported anti-aging properties of some plant sterols (Tada et al. 2009). Alternatively, low doses of toxins could potentially modulate stress response pathways such that the body is primed to combat other forms of environmental stress (hormesis), resulting in increased longevity (Gems \& Partridge 2008).

Previously, resistance to $C$. maculatus infestation has been shown to be due to the presence of vicilin-like 7S storage globulins in the seed coat (Silva et al. 2004) and cotyledon of $P$. vulgaris (Macedo et al. 1993). Here, we show that several secondary metabolites, present in the seed coats of both resistant and susceptible varieties of beans, can have a negative effect on the fitness of the seed parasite C. maculatus. Identification of the mechanisms by which plants defend themselves against pests is a key step in process of breeding resistant varieties of food legumes (Keneni et al. 2011).

\section{Acknowledgments}

This work was supported by the School of Life Sciences, University of Lincoln, United Kingdom. 


\section{References}

Abdel-Sabour AG, Obiadalla-Ali HA and AbdelRehim KA (2010) Genetic and chemical analyses of six cowpea and two Phaseolus bean species differing in resistance to weevil pest. Journal of Crop Science and Biotechnology 13: 53-60.

Audu SA, Mohammed I and Kaita HA (2007) Phytochemical screening of the leaves of Lophira lanceolata (Ochanaceae). Life Science Journal 4: 75-79.

Bekele AJ, Hassanali A (2001) Blend effects in the toxicity of the essential oil constituents of Ocimum kilimandscharicum and Ocimum kenyense (Labiateae) on two post-harvest insect pests. Phytochemistry 57: 385-391.

Chi Y, Salzman R, Balfe S, Ahn J, Sun W, Moon J, Yun D, Lee S, Higgins T and Pittendrigh B (2009) Cowpea bruchid midgut transcriptome response to a soybean cystatin - costs and benefits of counter defence. Insect. Molecular Biology 18: 97-110.

Crawley MJ (2002) Statistical Computing: An Introduction to Data Analysis Using S-Plus. John Wiley \& Sons, Ltd, Chichester, UK.

De Geyter E, Lambert E, Geelen D and Smagghe G (2007) Novel advances with plant saponins as natural insecticides to control pest insects. Pest Technology 1: 96-105.

Després L, David J, and Gallet C (2007) The evolutionary ecology of insect resistance to plant chemicals. Trends in Ecology \& Evolution 22: 298-307.

Dugravot S, Grolleau F, Macherel D, Rochetaing A, Hue B, Stankiewicz M, Huignard J and Lapied B (2003) Dimethyl disulphide exerts insecticidal neurotoxicity through mitochondrial dysfunction and activation of insect $\mathrm{K}_{\mathrm{ATP}}$ channels. Journal Neurophysiology 90: 259-270. 
Doughari JH (2012) Phytochemicals: Extraction Methods, Basic Structures and Mode of Action as Potential Chemotherapeutic Agents. In: Dr. Venketeshwer Rao (ed.) Phytochemicals - A Global Perspective of Their Role in Nutrition and Health. Agricultural and Biological Sciences edition. InTech, pp 1-32.

Edeoga H, Okwu D, and Mbaebie B (2005) Phytochemical constituents of some Nigerian medicinal plants. African Journal of Biotechnology 4: 685-688.

Eady PE, Wilson N, and Jackson M (2000) Copulating with multiple mates enhances female fecundity but not egg-to-adult survival in the bruchid beetle Callosobruchus maculatus. Evolution 54: 2161-2165.

Eady PE, Hamilton L and Lyons RE (2007) Copulation, genital damage and early death in Callosobruchus maculatus. Proceedings of the Royal Society B: Biological Sciences 274: 247-252.

Edde P and Amatobi C (2003) Seed coat has no value in protecting cowpea seed against attack by Callosobruchus maculatus (F.). Journal of Stored Products Research 39: 11-10. Fatokun CA Tarawali SA, Singh BB, Kormawa PM and Tamo M (2002) Challenges and opportunities for enhancing sustainable cowpea production. Proceedings of the World Cowpea Conference III held at the International Institute of Tropical Agriculture (IITA), Ibadan, Nigeria, 4-8 September 2000. IITA, Ibadan, Nigeria

Ferry A, Le Tron S, Dugravot S, and Cortesero A (2009) Field evaluation of the combined deterrent and attractive effects of dimethyl disulfide on Delia radicum and its natural enemies. Biological Control 49: 219-226.

Fenner M and Thompson K (2005) The Ecology of Seeds. Cambridge University Press. 
Gems D and Partridge L (2008) Stress-response hormesis and aging: "That which does not kill us makes us stronger”. Cell Metabolism, 7: 200-203.

Ha TJ, Lee BW, Park KH, Jeong SH, Kim H-T, Ko J-M, Baek I-Y and Lee JH (2014) Rapid characterisation and comparison of saponin profiles in the seeds of Korean Leguminous species using ultra performance liquid chromatography with photodiode array detector and electrospray ionisation/mass spectrometry (UPLC-PDA-ESI/MS) analysis. Food Chemistry 146: $270-277$.

Harborne J (1973) Phytochemical Methods. Chapman and Hall, London.

Hudaib T, Brown S, Goodman AM \& Eady PE (2013) Efficacy of artificial seeds in the delivery of bioactive compounds to the seed dwelling larvae of Callosobruchus maculatus (Coleoptera: Bruchidae). Arthropod-Plant Interactions 7: 527-533.

Hudaib T, Hayes W, Brown S and Eady PE (2010) Effect of seed moisture content and dlimonene on oviposition decisions of the seed beetle Callosobruchus maculatus. Entomologia Experimentalis Et Applicata 137(2): 120-125. doi: 10.1111/j.1570-7458.2010.01044.x Ishimoto M. \& Kitamura K (1989) Growth Inhibitory Effects of an a-Amylase Inhibitor from the Kidney Bean, Phaseolus vulgaris (L.) on Three Species of Bruchids (Coleoptera: Bruchidae). Applied Entomology and Zoology 24: 281-286.

Janson EM., Grebenok, R.J., Behmer, S.T. and Abbot, P., 2009. Same host-plant, different sterols: variation in sterol metabolism in an insect herbivore community. Journal of Chemical Ecology, 35:1309-1319.

Janzen, D.H. (1977) How southern cowpea weevil larvae (Bruchidae: Callosobruchus maculatus) die on nonhost seeds. Ecology 58: 921-927. 
Janzen, D.H., Juster, H.B., and Arthur Bell, E. (1977) Toxicity of secondary compounds to the seed-eating larvae of the bruchid beetle Callosobruchus maculatus. Phytochemistry 16: 223-227.

Jayaprakasha, G., Singh, R., and Sakariah, K. (2001) Antioxidant activity of grape seed (Vitis vinifera) extracts on peroxidation models in vitro. Food Chemistry 73:285-290.

Jing, X., Grebenok, R.J. and Behmer, S.T., 2012. Plant sterols and host plant suitability for generalist and specialist caterpillars. Journal of insect physiology 58:235-244.

Keneni, G., Bekele, E., Getu, E., Imtiaz, M., Damte, T., Mulatu, B. and Dagne, K. (2011) Breeding food legumes for resistance to storage insect pests: potential and limitations. Sustainability 3:1399-1415.

Kovats, E. (1958) Gas-chromatographische Charakterisierung organischer Verbindungen. Teil 1: Retentionsindices aliphatischer Halogenide, Alkohole, Aldehyde und Ketone. Helvetica Chimica Acta 41:1915-1932.

Macedo, M.L.R., Andrade, L.B.D.S., Moraes, R.A. and Xavier-Filho, J., 1993. Vicilin variants and the resistance of cowpea (Vigna unguiculata) seeds to the cowpea weevil (Callosobruchus maculatus). Comparative Biochemistry and Physiology Part C: Comparative Pharmacology 105: 89-94. 
Moraes, R., Sales, M., Pinto, M., Silva, L., Oliveira, A., Machado, O., Fernandes, K., and Xavier-Filho, J. (2000) Lima bean (Phaseolus lunatus) seed coat phaseolin is detrimental to the cowpea weevil (Callosobruchus maculatus). Brazilian Journal of Medical and Biological Research 33: 191-198.

Odeyemi OO, Masika P \& Afolayan A J (2008). A review of the use of phytochemicals for insect pest control. African Plant Protection 14: 1-7

Odebiyi OO. and Sofowora EA (1978) Phytochemical screening of Nigerian medicinal plants II. Lloydia, 41: 234-246.

Oliveira AEA, Sales MP, Machado OLT, Fernandes KVS, and Xavier-Filho J (1999) The toxicity of Jack bean (Canavalia ensiformis) cotyledon and seed coat proteins to the cowpea weevil (Callosobruchus maculatus). Entomologia Experimentalis Et Applicata 92: 249-255.

Onuh M and Onyenekwe R (2008) Assessment of inhibitory substances in the seed coat of some cowpea cultivars for resistance against Callosobruchus maculatus. Science World Journal 3: 15-19.

Porter SS (2013) Adaptive divergence in seed colour camouflage in contrasting soil environments. New Phytologist 197: 1311-1320.

Qiu Y-T, van Loon JJA and Roessingh P (1998) Chemoreception of oviposition inhibiting terpenoids in the diamondback moth Plutella xylostella. Entomologia Experimentalis et Applicata 87: 143-155.

Rattan RS (2010) Mechanisms of action of insecticidal secondary metabolites of plant origin. Crop Protection 29: 913-920. 
Rharrabe K, Sayan, F, and LaFont R (2010) Dietary effects of four phytoecdysteroids on growth and development of the Indian meal moth, Plodia interpunctella. Journal of Insect Science 10: 1-12.

Rodgerson L (1998). Mechanical defense in seeds adapted for ant dispersal. Ecology 79: $1669-1677$.

Salunke BK, Kotkar HM, Mendki PS, Upasani SM and Maheshwari VL (2005) Efficacy of flavonoids in controlling Callosobruchus chinensis (L.) (Coleoptera: Bruchidae), a postharvest pest of grain legumes. Crop Protection 24: 888-893.

Shade RE, Murdock LL, Foard DE and Pomeroy MA (1986) Artificial seed system for bioassay of cowpea weevil (Coleoptera: Bruchidae) growth and development. Environmental Entomology 15: 1286-1291.

Silva LB, Sales MP, Oliveira AE, Machado OL, Fernandes KV and Xavier-Filho J (2004) The seed coat of Phaseolus vulgaris interferes with the development of the cowpea weevil Callosobruchus maculatus (F.)(Coleoptera: Bruchidae)]. Anais da Academia Brasileira de Ciências 76: 57-65.

Soares EL, Freitas CDT, Oliveira JS, Sousa PAS, Sales MP, Barreto-Filho JDM, Bandeira GP and Ramos MV (2007) Characterization and insecticidal properties of globulins and albumins from Luetzelburgia auriculata (Allemao) Ducke seeds towards Callosobruchus maculatus (F.) (Coleoptera: Bruchidae). Journal of Stored Products Research 43: 459-467.

Souza A, Ferreira A, Perales J, Beghini, D, Fernandes K, Xavier-Filho J, Venancio T, and Oliveira A (2012) Identification of Albizia lebbeck seed coat chitin-binding vicilins (7S globulins) with high toxicity to the larvae of the bruchid Callosobruchus maculatus. Brazilian Journal of Medical and Biological Research 45: 118-124. 
Souza FH and Marcos-Filho J (2001) The seed coat as a modulator of seed-environment relationships in Fabaceae. Brazilian Journal of Botany 24: 365-375.

Srinivasan T and Durairaj C (2007) Biochemical basis of resistance in rice bean Vigna umbellata Thunb.(Ohwi and Ohashi) against Callasobruchus maculatus F. Journal of Entomology 4: 371-378.

Tada Y, Kanda N, Haratake A, Tobiishi M, Uchiwa H and Watanabe S (2009) Novel effects of diosgenin on skin aging. Steroids 74: 504-511.

Tallamy DW, Stull J, Ehresman NP, Gorski PM and Mason CE (1997) Cucurbitacins as feeding and oviposition deterrents to insects. Environmental Entomology 26: 678-683.

Umeozor OC (2005) Effect of the infection of Callosobruchus maculatus (Fab.) on the weight loss of stored cowpea (Vigna unguiculata (L.) Walp). Journal of Applied Sciences in Environmental Sanitation 9: 169-172.

Upasani SM, Kotkar HM, Mendki PS and Maheshwari (2003) Partial characterization and insecticidal properties of Ricinus communis L foliage flavonoids. Pest Management Science 59: $1349-1354$

Wilson K and Hill L (1989) Factors affecting egg maturation in the bean weevil Callosobruchus maculatus. Physiological Entomology 14: 115-126.

Zeng CL, Wang JB, Liu AH and Wu XM (2004). Seed coat microsculpturing changes during seed development in diploid and amphidiploid Brassica species. Annals of Botany 93: 555566. 


\section{TABLE 1}

Phytochemicals detected in the extracts of black-eyed bean seed-coat (BEB) and kidney-bean seed-coat $(\mathrm{KB}) ;+$ is positive, ++ is moderately positive, +++ is highly positive expressing the intensity of each phytochemical group in the extracts.

\begin{tabular}{|c|c|c|c|c|c|c|c|c|}
\hline \multirow[b]{2}{*}{ Phytochemical test } & \multicolumn{2}{|c|}{$\begin{array}{c}70 \% \\
\text { Ethanol }\end{array}$} & \multicolumn{2}{|c|}{$\begin{array}{c}100 \% \\
\text { Methanol }\end{array}$} & \multicolumn{2}{|c|}{$\begin{array}{c}100 \% \\
\text { Chloroform }\end{array}$} & \multicolumn{2}{|c|}{$\begin{array}{c}100 \% \\
\text { Acetone }\end{array}$} \\
\hline & $\begin{array}{r}\text { BE } \\
\text { B }\end{array}$ & KB & BEB & $\mathbf{K B}$ & BEB & KB & BEB & KB \\
\hline Saponin & ++ & +++ & ++ & & & & & + \\
\hline Tannins(Phloba) & + & ++ & & & & & & \\
\hline Phenolics & ++ & +++ & & ++ & & & & \\
\hline Terpenoids & + & +++ & & +++ & & & & \\
\hline Steroids & & & & & + & ++ & & \\
\hline Glycosides(Cardiac) & + & ++ & & & & & & \\
\hline Flavonoids & ++ & +++ & & ++ & & & & \\
\hline Alkaloids 1 & ++ & +++ & & ++ & & & & \\
\hline Alkaloids 2 & & & & ++ & & & & \\
\hline
\end{tabular}

\section{Figure captions}

Fig. 1 Total Ion chromatograms (TIC) of (a) 100\% methanol extract of black-eyed beans and (b) $100 \%$ Methanol extract of kidney beans.

Fig. 2 Mean + SE a) fecundity, b) development time (days), c) egg-to-adult survival d) male offspring elytra length (mm), e) male offspring longevity (days) and f) male offspring 
lifespan (days) of C. maculatus in relation to experimental treatment. BEBC, BEBM and BEBE represent the black-eyed bean chloroform, methanol and ethanol extracts whilst $\mathrm{KBC}$, $\mathrm{KBM}$ and $\mathrm{KBC}$ represent the kidney bean chloroform, methanol and ethanol extracts. 